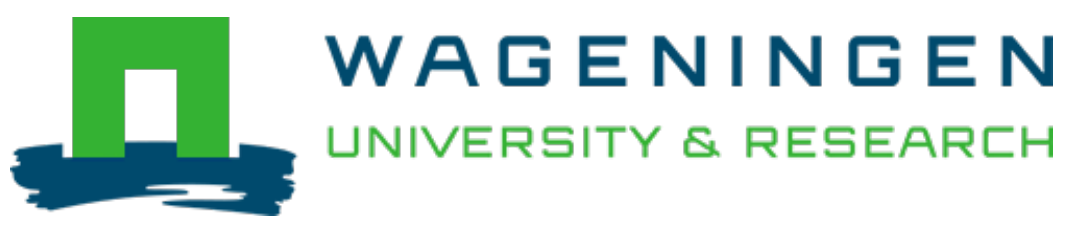

\title{
The phenolic compounds, tocopherols, and phytosterols in the edible oil of guava (Psidium guava) seeds obtained by supercritical $\mathrm{CO}_{2}$ extraction
}

\author{
Journal of Food Composition and Analysis \\ Narváez-Cuenca, Carlos Eduardo; Inampues-Charfuelan, Mary Lucía; Hurtado-Benavides, Andrés Mauricio; \\ Parada-Alfonso, Fabián; Vincken, Jean Paul \\ https://doi.org/10.1016/j.jfca.2020.103467
}

This article is made publicly available in the institutional repository of Wageningen University and Research, under the terms of article $25 \mathrm{fa}$ of the Dutch Copyright Act, also known as the Amendment Taverne. This has been done with explicit consent by the author.

Article $25 \mathrm{fa}$ states that the author of a short scientific work funded either wholly or partially by Dutch public funds is entitled to make that work publicly available for no consideration following a reasonable period of time after the work was first published, provided that clear reference is made to the source of the first publication of the work.

This publication is distributed under The Association of Universities in the Netherlands (VSNU) 'Article $25 \mathrm{fa}$ implementation' project. In this project research outputs of researchers employed by Dutch Universities that comply with the legal requirements of Article 25fa of the Dutch Copyright Act are distributed online and free of cost or other barriers in institutional repositories. Research outputs are distributed six months after their first online publication in the original published version and with proper attribution to the source of the original publication.

You are permitted to download and use the publication for personal purposes. All rights remain with the author(s) and / or copyright owner(s) of this work. Any use of the publication or parts of it other than authorised under article $25 \mathrm{fa}$ of the Dutch Copyright act is prohibited. Wageningen University \& Research and the author(s) of this publication shall not be held responsible or liable for any damages resulting from your (re)use of this publication.

For questions regarding the public availability of this article please contact openscience.library@wur.nl 
Original Research Article

\title{
The phenolic compounds, tocopherols, and phytosterols in the edible oil of guava (Psidium guava) seeds obtained by supercritical $\mathrm{CO}_{2}$ extraction
}

\author{
Carlos-Eduardo Narváez-Cuenca ${ }^{\mathrm{a}, *}$, Mary-Lucía Inampues-Charfuelan ${ }^{\mathrm{a}}$, \\ Andrés-Mauricio Hurtado-Benavides ${ }^{\mathrm{b}}$, Fabián Parada-Alfonso ${ }^{\mathrm{a}}$, Jean-Paul Vincken ${ }^{\mathrm{c}}$ \\ ${ }^{a}$ Universidad Nacional de Colombia, Sede Bogotá, Facultad de Ciencias, Departamento de Química, Food Chemistry Research Group, Carrera 30 No 45-03, Bogotá, \\ Colombia \\ ${ }^{\mathrm{b}}$ Laboratorio de fluidos supercríticos e ingredientes naturales, Universidad de Nariño, 520001 Pasto, Colombia \\ ${ }^{\mathrm{c}}$ Laboratory of Food Chemistry, Wageningen University, P.O. Box 17, 6700 AA, Wageningen, The Netherlands
}

\section{A R T I C L E I N F O}

\section{Keywords:}

Supercritical fluid extraction

Agroindustrial by-products

Agroindustrial waste

Tropical fruit

Linolenic acid

Vanillin

Cinnamaldehyde

\begin{abstract}
A B S T R A C T
An edible oil was obtained from guava seeds by supercritical $\mathrm{CO}_{2}$ extraction. The oil was characterized by its fatty acid composition, physicochemical properties, and the contents of phenolic, miscellaneous, phytosterol, and tocopherol compounds. The oil, obtained with a yield of $8.6 \pm 1.2 \mathrm{~g}$ oil $/ 100 \mathrm{~g}$ guava seeds, had a high content of linoleic acid $(78.5 \%, w / w)$, followed by that of oleic acid $(13.8 \%, w / w)$. The guava seed oil had physicochemical properties comparable to those published in previous research, except for the low stability to oxidation. The chromatographic profile of the phenolic and miscellaneous compounds was dominated by vanillin (9.6 $\pm 0.3 \mathrm{mg} / 100 \mathrm{~g}$ oil) and cinnamaldehyde $(9.4 \pm 0.2 \mathrm{mg} / 100 \mathrm{~g}$ oil), followed by vanillic acid $(3.9 \pm 0.4 \mathrm{mg} / 100 \mathrm{~g}$ oil $)$, cinnamic acid $(2.4 \pm 0.1 \mathrm{mg} / 100 \mathrm{~g}$ oil $)$, and minor amounts of other phenolic aldehydes. Among the phytosterols and tocopherols, $\beta$-sitosterol $(1048.9 \pm 48.4 \mathrm{mg} / 100 \mathrm{~g}$ oil) and $\gamma$-tocopherol $(82.6 \pm 3.7 \mathrm{mg} / 100 \mathrm{~g}$ oil $)$ were the most abundant. The low oxidative stability of the oil compared to that published in previous reports might reflect the high complexity of this matrix. This oil might have applications, directly or after blending with more stable edible oils.
\end{abstract}

\section{Introduction}

Guava (Psidium guava) is a perennial tree native to South America, and its leaves, bark, and roots are used in traditional medicine (Barbalho et al., 2012). The fruit has considerable amounts of vitamin C, carotenoids, and phenolic compounds (Medina and Herrero, 2016). The fruit is consumed fresh and used in the food industry to produce nectars, jams, jellies, and syrups. In the last ten years, Colombia has produced more than 80,000 tons/year of guava fruit with nearly 10,000 ha dedicated to this crop. As projected by the Colombian government, in the near future, it will be necessary to produce 200,000 tons/year of guava fruit because of guava jelly production (Agronet, 2019). During guava fruit processing, seeds are a by-product that account for up to $30 \%(w / w)$ of the fruit weight (Iha et al., 2018), representing an environmental and phytosanitary problem. Guava seeds, however, have potential use as a source of edible oil and bioactive compounds (Da Silva and Jorge, 2014).

The oil extracted from guava seeds with organic solvents contains bioactive compounds, including phenolic compounds (e.g., $4.8 \mathrm{mg} p$ - coumaric acid/100 g oil), phytosterols (e.g., up to $437.6 \mathrm{mg} \beta$-sitosterol/100 g oil), and tocopherols (e.g., up to $10.7 \mathrm{mg} \alpha$-tocopherol/ $100 \mathrm{~g}$ oil) (Da Silva and Jorge, 2014; Malacrida and Jorge, 2013; Piombo et al., 2006). Furthermore, when the oil was extracted with either organic solvents or supercritical $\mathrm{CO}_{2}$ (with ethanol as a co-solvent), polyunsaturated fatty acids were reported to account for at least $52 \%(w / w)$ of the total fatty acid profile (Arain et al., 2017; CastroVargas et al., 2011; Cerón et al., 2016; Da Silva and Jorge, 2014; Habib, 1986; Tha et al., 2018; Malacrida and Jorge, 2013; Opute, 1978; Prasad and Azeemoddin, 1994). Concentrations of phenolic compounds, phytosterols, and tocopherols as well as those of polyunsaturated fatty acids in guava seed oil are higher or comparable to those found in other fruit seed oils, including those extracted from the seeds of the Isabela grape (Vitis labrusca L.), melon (Cucumis melo var. inodorus Naudin), passion fruit (Passiflora edulis Sims), pumpkin (Cucurbita moschata), soursop (Annona muricata L.), and tomato (Solanum lycopersicum) (Da Silva and Jorge, 2014).

Oil extraction by supercritical $\mathrm{CO}_{2}$ is considered to be fast and efficient, with low or no use of organic solvents, yielding a product in

\footnotetext{
* Corresponding author at: Departamento de Química, Universidad Nacional de Colombia, AA 14490 Bogotá, Colombia

E-mail address: cenarvaezc@unal.edu.co (C.-E. Narváez-Cuenca).
} 
which degradation of components, such as fatty acids and bioactive compounds, is lower compared to that of other extraction techniques (Sahena et al., 2009). Oil has been obtained from guava seeds by supercritical $\mathrm{CO}_{2}$ extraction under different conditions of pressure and temperature to find the optimum extraction conditions, and its fatty acid profile was evaluated (Castro-Vargas et al., 2011; Cerón et al., 2016). Because supercritical fluid extraction has been shown to have an important effect on the type and concentration of bioactive compounds present in an extract compared to that obtained by organic solvents, e.g., the Soxhlet method (Mezzomo et al., 2010), it was hypothesized that a different composition might be obtained when extracting oil from guava seeds by supercritical $\mathrm{CO}_{2}$ extraction. To the best of our knowledge, nevertheless, no information on the composition of bio-active compounds, such as phenolic compounds, phytosterols, and tocopherols, in guava seed oil obtained by supercritical $\mathrm{CO}_{2}$ extraction is available. The aim of this research was, therefore, to characterize an edible oil obtained from guava seeds by supercritical $\mathrm{CO}_{2}$ extraction on such features.

\section{Materials and methods}

\subsection{Plant material}

Guava seeds were obtained from three different batches from a food company located at the Department of Nariño, southwest Colombia, Andina de conservas LTDA. Once in the lab, guava seeds $(12.0 \mathrm{~kg})$ were washed with distilled water and dried in an oven at $50^{\circ} \mathrm{C}$ for $48 \mathrm{~h}$ to yield $5.1 \mathrm{~kg}$ of dried seeds. Seeds were ground, sieved, and stored in hermetically sealed plastic bags at room temperature in a desiccator containing silica gel until extraction with supercritical $\mathrm{CO}_{2}$. The ground and sieved guava seeds had a moisture content of $8.05 \pm 0.52 \%$, an average particle diameter (dap) of $490.02 \pm 1.2 \mu \mathrm{m}$, true ( $\rho \mathrm{t}$ ) and apparent densities ( $\rho$ a) of $1,020.27 \pm 10.61$ and $616.17 \pm 8.64 \mathrm{~kg} /$ $\mathrm{m}^{3}$, respectively, and a porosity $(\varepsilon)$ of 0.3960 . The seeds had a crude fat content of $9.1 \pm 0.3 \mathrm{~g}$ oil $/ 100 \mathrm{~g}$ seeds as evaluated by the Soxhlet method with $n$-hexane as the extraction solvent.

\subsection{Reagents and standards}

Ultra-high-performance liquid chromatography (UHPLC)/mass spectrometry (MS)-grade acetonitrile containing $0.1 \%(v / v)$ formic acid and UHPLC/MS-grade water containing $0.1 \%(v / v)$ formic acid were obtained from Biosolve BV (Valkenswaard, The Netherlands). $\mathrm{CO}_{2}(99.8$ $\%$ was obtained from Oxígenos del sur LTDA (Pasto, Nariño, Colombia). Helium (99.99\%) was purchased from Linde (EKITEC, Pasto, Colombia). A fatty acid methyl ester standard was obtained from RESTEK (Benner Circle, Bellefonte, USA) and was a mixture of 37 components, from C4:0 to C24:1. Gallic acid, vanillin, 4-hydroxy-3methoxycinnamaldehyde (coniferyl aldehyde), trans-3,5-dimethoxy-4hydroxycinnamaldehyde (sinapaldehyde), trans-cinnamic acid, and trans-cinnamaldehyde were purchased from Sigma-Aldrich Chemie GmbH (Steinheim, Germany). Vanillic acid and 3,5-dimethoxy-4-hydroxybenzaldehyde (syringaldehyde) were obtained from Roth (Karlsruhe, Germany), and 4-hydroxybenzaldehyde was obtained from Alfa Aesar (Karlsruhe, Germany). Sodium carbonate, Folin-Ciocalteu reagent, and other solvents were purchased from Merck ${ }^{\circledR}$ (Darmstadt, Germany). Cholesterol was obtained from Sigma Aldrich (St. Louis, MO, United States).

\subsection{Supercritical $\mathrm{CO}_{2}$ extraction}

A Waters SFE-500 (Milford, Connecticut, USA) equipped with a $500 \mathrm{~mL}$ extraction cell was used. The pressure and temperature of the system and $\mathrm{CO}_{2}$ flow were controlled by Process Suite software (version 5.9, Milford, Connecticut, USA). Supercritical $\mathrm{CO}_{2}$ extraction was performed on $250.0 \mathrm{~g}$ of ground and dried guava seeds at $52{ }^{\circ} \mathrm{C}$ and
$35.7 \mathrm{MPa}$ (density of $\mathrm{CO}_{2}: 895 \mathrm{~kg} / \mathrm{m}^{3}$ ) at a constant flow of $30 \mathrm{~g} \mathrm{CO}_{2} /$ $\mathrm{min}$ for $150 \mathrm{~min}$ according to an optimization process extraction evaluated by Cerón et al. (2016). Extraction was performed in triplicate using three different samples. After supercritical $\mathrm{CO}_{2}$ extraction, an oil was obtained $(21.4 \pm 0.3 \mathrm{~g})$. The extracted oil was aliquoted into $\sim 2 \mathrm{~g}$ aliquots in amber glass vials, flushed with $\mathrm{N}_{2}$ gas, and stored at $-20{ }^{\circ} \mathrm{C}$ until analyses were completed.

\subsection{Fatty acid composition of guava seed oil}

The fatty acid composition was evaluated after interesterification with methanol under acidic conditions, and analysis of the fatty acid methyl esters was conducted with gas chromatography (GC) with a flame ionization detector (FID) as described elsewhere (HurtadoBenavides et al., 2016). Esterification with methanol was performed by incubating $200 \mu \mathrm{L}$ of oil with $5 \mathrm{~mL}$ of $5 \%(v / v) \mathrm{HCl}$ in methanol at $50{ }^{\circ} \mathrm{C}$ for $8 \mathrm{~h}$. Next, the fatty acid methyl esters were extracted twice with $2 \mathrm{~mL} n$-hexane. Then, the $n$-hexane extract was analysed by GC-FID. A Shimadzu GC 17A version 3 instrument (Shimadzu, Kyoto, Japan) equipped with a split/splitless injector, a DB-WAX column $(30 \mathrm{~m} \times 0.25 \mathrm{~mm}$ I.D., and $0.25 \mu \mathrm{m}$ df, J\&W Agilent Scientific, Folsom, CA, USA), and a FID was used. The $n$-hexane extract $(1 \mu \mathrm{L})$ was injected in split mode (split ratio $1: 10$ ) at $250^{\circ} \mathrm{C}$. Helium was used as the carrier gas at $1 \mathrm{~mL} / \mathrm{min}$. Separation of compounds was performed by using an oven temperature programme. The temperature of the oven was held at $40{ }^{\circ} \mathrm{C}$ for $5 \mathrm{~min}$ and then increased to $250^{\circ} \mathrm{C}$ at a rate of $5^{\circ} \mathrm{C} / \mathrm{min}$. Next, the temperature was dropped to starting conditions and equilibrated for at least $5 \mathrm{~min}$. The FID was operated at $280^{\circ} \mathrm{C}$ with $300 \mathrm{~mL} / \mathrm{min}$ hydrogen and $30 \mathrm{~mL} / \mathrm{min}$ air. The system was controlled by using Shimadzu Class VP 4.3 software (Kyoto, Japon). The identification of fatty acid methyl esters was performed by comparing their retention indexes against those of authentic standards. Quantification was performed by calculating the relative chromatographic area.

\subsection{Physicochemical properties of guava seed oil}

The density at $20^{\circ} \mathrm{C}$ (AOCS Cc 10c-95), refractive index at $25^{\circ} \mathrm{C}$ (AOCS Cc 7-25), saponification number (AOAC 920.160), iodine value (AOAC 993.20), peroxide value (AOAC 965.33), and acid value (AOCS Cd 3d-63) were evaluated for the extracted oil (AOAC, 1995; AOCS and Firestone, 2009).

The oxidative stability of the oil was evaluated in a Metrohm Professional Rancimat model 892 (Herisau, Switzerland), controlled with StabNet 1.0 Full software (Herisau, Switzerland). The sample ( $3.0 \mathrm{~g}$ oil) was oxidized at $100{ }^{\circ} \mathrm{C}$ with an air flow rate of $20 \mathrm{~L} / \mathrm{min}$. After oxidation, the induction time was evaluated.

\subsection{Extraction of phenolic compounds from the oil}

A methanolic extract was obtained from the oil (Da Silva and Jorge, 2014) and used for both identification and quantitation of individual phenolic compounds and for the determination of the total phenolic content. Oil (400 mg) was extracted with $1.2 \mathrm{~mL} 100 \%$ ( $v / v$ methanol by vortexing $1 \mathrm{~min}, 20^{\circ} \mathrm{C}$ followed by shaking in a Thermomixer comfort shaker $1000 \mathrm{~s}^{-1} ; 10 \mathrm{~min} ; 20^{\circ} \mathrm{C}$ ) (Eppendorf AG, Hamburg, Germany). Next, the oil-methanol mixture was centrifuged $(18,000 \times$ g; $5 \mathrm{~min} ; 20^{\circ} \mathrm{C}$ ), and the upper layer (methanolic layer) was collected and stored at $10^{\circ} \mathrm{C}$. The remaining oil was extracted as described above, four times in total. After four extractions, $95 \%$ of the polyphenols were extracted, as measured at 290 and $310 \mathrm{~nm}$. The four supernatants were pooled together to obtain a methanolic extract (nonconcentrated extract). This nonconcentrated extract was analysed for the identification and quantitation of individual phenolic compounds as well as for the total phenolic content. An aliquot of the nonconcentrated extract was concentrated to $10 \%$ of the initial volume in a SpeedVac Savant ISS110 concentrator (Thermo Scientific, San Jose, CA, USA), which was used 
for the identification and quantitation of individual phenolic compounds.

\subsection{Identification of individual phenolic and miscellaneous compounds in the methanolic extract from guava seed oil by RP-UHPLC-DAD-HESI-MS/ $M S$ and RP-UHPLC-HESI-IT-FTMS}

Tentative annotation of compounds was performed by two strategies: reversed phase (RP)-ultra-high-performance liquid chromatography (UHPLC) with diode array detection (DAD) and heated electrospray ionization (HESI) tandem mass spectrometry (MS/MS) detection, by using a linear triple quadrupole, and by RP-UHPLC-HESIion trap (IT)-Fourier transformed mass spectrometry (FTMS). Special attention was paid to the analysis of phenolic compounds.

\subsubsection{RP-UHPLC-DAD-HESI-MS/MS}

UV spectra, precursor ions, and product ions of chromatographic peaks were obtained. A Thermo Accela UHPLC system (Thermo Scientific, San Jose, CA, USA) equipped with a pump, an autosampler, a degasser, and both in-line DAD and HESI-MS/MS detectors was used. Extracts (concentrated and nonconcentrated, $2 \mu \mathrm{L}$ ) were injected into an Acquity UPLC BEH C18 column $(150 \mathrm{~mm} \times 2.1 \mathrm{~mm}$, particle size $1.7 \mu \mathrm{m}$, Waters, Milford, MA, USA) coupled to a precolumn $\left(10 \mathrm{~mm} \times 2 \mathrm{~mm}, 3 \mu \mathrm{m}\right.$, Waters, Milford, MA, USA) operated at $45^{\circ} \mathrm{C}$ and eluted by using a gradient of two eluents. Eluent A was water/ acetonitrile/formic acid (99:0.9:0.1, $v / v / v)$, and eluent B was acetonitrile/formic acid (99.9:0.1, v/v). The elution programme was isocratic at $5 \%$ B for $1.5 \mathrm{~min}$, a linear gradient from 15 to $45 \%$ B from 1.5 to $20 \mathrm{~min}$, a linear gradient from 45 to $100 \%$ B from 20 to $21 \mathrm{~min}$, isocratic at $100 \%$ B from 21 to 24 min, a linear gradient from 100 to $5 \%$ B from 24 to $25 \mathrm{~min}$, and isocratic at the starting conditions (5\% B) from 25 to $30 \mathrm{~min}$. The flow rate was $400 \mu \mathrm{L} / \mathrm{min}$. The eluate was directed into the $\mathrm{DAD}$, and the UV-vis spectrum of each chromatographic peak was recorded at wavelengths between 200 and $700 \mathrm{~nm}$. After passing through the DAD, the flow was directed into the HESI (Thermo Scientific, San Jose, CA, USA) probe coupled to a Thermo Scientific LTQ-XL (Thermo Scientific, San Jose, CA, USA) mass spectrometer, operated in both positive and negative modes over the $\mathrm{m} / \mathrm{z}$ range 120-2,000. Data-dependent MS/MS analysis was performed using collision-induced dissociation with a normalized collision energy of $35 \%$. After tuning with vanillin, the following conditions were set: heater temperature, $250^{\circ} \mathrm{C}$; source voltage, $4.5 \mathrm{kV}$; ion transfer tube temperature, $350{ }^{\circ} \mathrm{C}$; sheath and auxiliary gas flow (both $\mathrm{N}_{2}$ ), 40 arbitrary units and 20 arbitrary units, respectively. Data were processed using Xcalibur 2.2 (Thermo Scientific, San Jose, CA, USA).

\subsubsection{RP-UHPLC-HESI-IT-FTMS}

Using this strategy, the exact molecular mass of each chromatographic peak was assessed. A Vanquish UHPLC system (Thermo Scientific, San Jose, CA, USA) equipped with a pump, an autosampler, a degasser, an eluent preheater, a post-column cooler, and HESI-IT-FTMS was used. The nonconcentrated methanolic extract was diluted 10 times with methanol and injected into the system. The injection volume, characteristics of the column, gradient, and flow rate were the same as those described above for the RP-UHPLC-DAD-HESI-MS/MS analysis. The eluent preheater and the post-column cooler were set at 45 and $40{ }^{\circ} \mathrm{C}$, respectively. Half of the flow was directed into a Thermo Q Exactive Focus hybrid quadrupole-orbitrap mass spectrometer (Thermo Scientific, San Jose, CA, USA) equipped with a HESI probe. Full MS data were recorded in both negative and positive ionization modes over a range of $m / z 100-1,500$ at a resolution of 70,000. The heater temperature was $280^{\circ} \mathrm{C}$, the source voltage was $2.8 \mathrm{kV}$, the ion transfer tube temperature was $320^{\circ} \mathrm{C}$, and the S-lens RF level was $50 . \mathrm{N}_{2}$ was used as the sheath gas and auxiliary gas at flow rates of 30 and 20 arbitrary units, respectively. Data processing was performed using Xcalibur 2.2 (Thermo Scientific, San Jose, CA, USA).

\subsection{Quantification of individual phenolic and miscellaneous compounds by RP-UHPLC-DAD}

Identified compounds were quantified by the external standard method with authentic standards under the conditions described under subtitle RP-UHPLC-DAD-HESI-MS/MS. To increase sensitivity, the absorbance of the eluate was recorded at several wavelengths, corresponding to the absorption maxima of chromatographic peaks: 276, $284,290,292,308,340$, and $345 \mathrm{~nm}$. For phenolic compound quantification, calibration curves were generated at five concentrations for vanillic acid at $292 \mathrm{~nm}$ (from 0.1 to $5.0 \mu \mathrm{g} / \mathrm{mL}$ ), 4-hydroxybenzaldehyde at $284 \mathrm{~nm}$ (from 0.3 to $5.0 \mu \mathrm{g} / \mathrm{mL}$ ), vanillin at $308 \mathrm{~nm}$ (from 0.3 to $20.0 \mu \mathrm{g} / \mathrm{mL}$ ), syringaldehyde at $308 \mathrm{~nm}$ (from 0.2 to $5.0 \mu \mathrm{g} / \mathrm{mL}$ ), coniferyl aldehyde at $340 \mathrm{~nm}$ (from 0.1 to $20.0 \mu \mathrm{g} / \mathrm{mL}$ ), and sinapyl aldehyde at $345 \mathrm{~nm}$ (from 0.1 to $10.0 \mu \mathrm{g} / \mathrm{mL}$ ). For miscellaneous compound quantification, calibration curves were generated with cinnamic acid at $276 \mathrm{~nm}$ (from 0.1 to $20.0 \mu \mathrm{g} / \mathrm{mL}$ ) and cinnamaldehyde at $290 \mathrm{~nm}$ (from 0.1 to $20.0 \mu \mathrm{g} / \mathrm{mL}$ ). In all cases, the linearity of the calibration curves was verified not only by the calculation of the $\mathrm{R}^{2}$ values but also by checking for any change in slope in the lower and upper limits. The limit of detection (LOD) was visually evaluated by lowering the concentration of each analyte and evaluating the minimum concentration in which the response was different from the noise. The limit of quantification (LOQ) was evaluated by finding the minimum concentration at which the peak area response and the concentration of each analyte showed linearity. Information on the calibration curve, LOD, and LOQ of each compound is given in Supplementary Table S1. The concentration of each compound was expressed as $\mathrm{mg} / 100 \mathrm{~g}$ oil. Each measurement was replicated three times.

\subsection{Determination of the total phenolic content of guava seed oil}

The total phenolic content was measured as described by Waterhouse (2002). Nonconcentrated extract $20 \mu \mathrm{L}$ was placed in a $2 \mathrm{~mL}$ Eppendorf plastic tube and mixed with $1580 \mu \mathrm{L}$ of water and $100 \mu \mathrm{L}$ of undiluted Folin-Ciocalteu reagent. The mixture was vortexed for $20 \mathrm{~s}$ and held at $20^{\circ} \mathrm{C}$ for $8 \mathrm{~min}$. After adding $300 \mu \mathrm{L}$ of $20 \%(w / v)$ aqueous $\mathrm{Na}_{2} \mathrm{CO}_{3}$, the mixture was vortexed for $20 \mathrm{~s}$ and left to stand in darkness for $2 \mathrm{~h}$. The absorbance of the solution was recorded at $765 \mathrm{~nm}$ on a spectrophotometer (Genesys $10 \mathrm{UV}$, Thermo Electron Corporation, Madison, WI, USA). A calibration curve was generated by using a standard solution of gallic acid with concentrations ranging from 50 to $500 \mu \mathrm{g} / \mathrm{mL}$ (six data points, $\mathrm{R}^{2}=0.999$ ). The total phenolic content was determined in triplicate and expressed as mg gallic acid equivalents $/ 100 \mathrm{~g}$ oil.

\subsection{Phytosterols and tocopherols of guava seed oil}

An extract prepared in dichloromethane was obtained from the oil and used for the identification and quantitation of phytosterols and tocopherols by GC-MS (Matthaus and Ozcan, 2011. The oil $(100 \mu \mathrm{L})$ was extracted twice with dichloromethane $(1000 \mu \mathrm{L})$ and analysed by GC-MS. Because no saponification was performed towards the extract, only the free phytosterol and tocopherol fractions were determined. A Shimadzu QP2010S (Shimadzu Scientific Corporation, Columbia, MD, USA) equipped with a split/splitless injector, a SHXRI-5MS column (Shimadzu, $30 \mathrm{~m} \times 0.25 \mathrm{~mm} \times 0.25 \mu \mathrm{m}$, Columbia, MD, USA) and a mass detector QP2010S with an electron impact ionization source operated at $70 \mathrm{eV}$ in full scan mode was used. The dichloromethane extract $(1 \mu \mathrm{L})$ was injected in split mode (split ratio $1: 10)$ at $270{ }^{\circ} \mathrm{C}$. Helium was used as the carrier gas at $1 \mathrm{~mL} / \mathrm{min}$. The separation of compounds was performed by using an oven temperature programme. The temperature of the oven was held at $100^{\circ} \mathrm{C}$ for $2 \mathrm{~min}$ and then increased to $300^{\circ} \mathrm{C}$ at a rate of $10^{\circ} \mathrm{C} / \mathrm{min}$ for $20 \mathrm{~min}$. Next, the temperature was maintained at $300^{\circ} \mathrm{C}$ for $15 \mathrm{~min}$ before being returned to 
starting conditions and equilibrated for at least $5 \mathrm{~min}$. The system was controlled by using Shimadzu LabSolutions GC-MS Ver 2.7 software (Columbia, MD, USA). Tentative identification of phytosterols and tocopherols was performed by comparing both their retention indexes and their MS spectra in the NIST database. The thresholds of a deviation in the retention index lower than $3 \%$ and a mass spectral match higher than $85 \%$ were applied. Quantification was performed by the internal standard method with cholesterol as the internal standard. The concentration of each compound was expressed as mg/100 g oil. Each measurement was replicated three times.

\subsection{Statistical analysis}

The results are reported as the average of three replicates $(n=3)$ and the standard deviation (SD). The yields of the extract obtained by $\mathrm{CO}_{2}$ supercritical fluid extraction and by the Soxhlet method were compared by a two-tailed Student's $t$-test $(p<0.05)$ in Microsoft Excel.

\section{Results}

\subsection{Extraction yield, fatty acid composition, and physicochemical properties of guava seed oil}

Oil from guava seeds extracted with supercritical $\mathrm{CO}_{2}$ was obtained with a yield of $8.6 \pm 1.2 \mathrm{~g}$ oil $100 \mathrm{~g}$ guava seeds (Table 1 ). This yield was similar (no significant different, $\mathrm{p}>0.05$ ) to that obtained when the extraction was performed by the Soxhlet method $(9.1 \pm 0.3 \mathrm{~g}$ oil/ $100 \mathrm{~g}$ guava seeds). Linolenic acid was the predominant fatty acid in the extracted guava seed oil, followed by oleic acid (Table 1). Polyunsaturated fatty acids accounted for $78.5 \%(w / w)$, with saturated fatty acids representing only $13.8 \%(w / w)$. The physicochemical features of the obtained oil are presented in Table 1 .

\subsection{Identification and quantification of phenolic and miscellaneous compounds in the methanolic extract of guava seed oil}

After analysing the methanolic extract of guava seed oil, twelve chromatographic peaks were observed (Fig. 1). These chromatographic peaks accounted for $98 \%$ of the total area as evaluated at $284 \mathrm{~nm}$. The other chromatographic peaks represented less than $1 \%$ of the total area. Among those twelve peaks, one compound was annotated as a phenolic acid, five as phenolic aldehydes, three as miscellaneous compounds, and three as unidentified (Fig. 1, Tables 2,3).

\subsubsection{Identification of phenolic compounds}

On the one hand, compound $\mathbf{2}$ was identified as a phenolic acid. On the other hand, compounds $\mathbf{3}$ and 5-8 were annotated as phenolic aldehydes. Chromatographic (retention time), spectroscopic (UV-vis), and spectrometric (precursor ions and product ions in both positive and negative modes) information is given in Table 2.

Compound 2 with the precursor ion $[\mathrm{M}-\mathrm{H}]^{-}$at $m / z 167$ yielded a product ion $\left[\mathrm{M}-\mathrm{CO}_{2}-\mathrm{H}\right]^{-}$at $m / z 123$ as the base peak in $\mathrm{MS}^{2}$ as well as a product ion at $\mathrm{m} / \mathrm{z} 108$, corresponding to $\left[\mathrm{M}-\mathrm{CO}_{2}-\mathrm{CH}_{3}-\mathrm{H}\right]^{-}$. Furthermore, fragmentation in positive mode of compound 2 gave the product ion $\left[\mathrm{M}-\mathrm{CO}_{2}+\mathrm{H}\right]^{+}$as the base peak.

Fragmentation in positive mode of the precursor ions of compounds 3 and 5-8 yielded product ions at $m / z 95,125,155,151$, and 181, respectively, corresponding, in all cases, to $[\mathrm{M}-\mathrm{CO}+\mathrm{H}]^{+}$. The neutral loss of 28 a.m.u. (CO moiety) was also observed in negative mode after fragmentation of the precursor ions of compounds $\mathbf{5}$ and $\mathbf{7}$ to produce $\mathrm{m} / \mathrm{z} 123$ and $149[\mathrm{M}-\mathrm{CO}-\mathrm{H}]^{-}$. The neutral loss of 15 a.m.u. observed after fragmentation of precursor ions in negative mode of compounds $\mathbf{5}$, 7 , and 8 was attributed to a $\mathrm{CH}_{3}$ moiety. The product ion in the negative mode of compound 7 at $\mathrm{m} / \mathrm{z} 134$ was assumed to correspond to $\left[\mathrm{M}-\mathrm{CO}-\mathrm{CH}_{3}-\mathrm{H}\right]^{-}$. Additionally, a neutral loss of 30 a.m.u. was observed when precursor ions of compounds $\mathbf{6}$ and $\mathbf{8}$ were fragmented in negative mode was attributed to the ion $\left[\mathrm{M}-2 \mathrm{CH}_{3}-\mathrm{H}\right]^{-}$. This ion was produced in both cases in the $\mathrm{MS}^{2}$ spectra as the base peak.

The mentioned fragmentation pattern, together with the relatively low molecular weight and UV-vis spectra of compound 2, was indicative of a phenolic acid, while such features for compounds $\mathbf{3}$ and 5-8 allowed for the annotation of them as phenolic aldehydes (Table 2). Accordingly, compound $\mathbf{2}$ was annotated as vanillic acid. Likewise, compound $\mathbf{3}$ was annotated as 4-hydroxybenzaldehyde, compound $\mathbf{5}$ as vanillin, compound 6 as syringaldehyde, compound 7 as coniferylaldehyde, and compound $\mathbf{8}$ as sinapaldehyde. Further evaluation of the retention time, UV-vis spectra, precursor ion, and product ions of authentic standards (Table 2) together with accurate mass evaluation (Table 3) confirmed this annotation.

\subsubsection{Quantification of phenolic compounds}

Two of the identified phenolic compounds accounted for $81 \%(w /$ $w$ ) of the total concentration (Table 4). Within the phenolic compound class, vanillin $(9.6 \pm 0.3 \mathrm{mg} / 100 \mathrm{~g}$ oil) was the most abundant, followed by vanillic acid $(3.9 \pm 0.4 \mathrm{mg} / 100 \mathrm{~g}$ oil $)$. The total amount of individual phenolic compounds ( $16.7 \pm 0.3 \mathrm{mg} / 100 \mathrm{~g}$ oil) (Table 4) was lower than that found with the Folin-Ciocalteu method $(263.1 \pm 18.7 \mathrm{mg}$ gallic acid equivalents $/ 100 \mathrm{~g}$ oil $)$.

\subsubsection{Identification and quantification of miscellaneous compounds}

Although not belonging to the family of phenolic compounds, spectroscopic and spectrometric data of chromatographic peaks 10-12 (Tables 2 and 3) revealed that these compounds were abscisic acid, cinnamic acid, and cinnamaldehyde, respectively. When assessing the phenolic profile, the non-phenolic compounds cinnamaldehyde and cinnamic acid were found at concentrations comparable to those of vanillin and vanillic acid, respectively (Table 4).

\subsection{Identification and quantification of phytosterols and tocopherols}

Phytosterols and tocopherols were tentatively identified based on the evaluation of retention index and MS spectra coincident with information from the NIST database. Among the identified phytosterols, $\beta$-sitosterol appeared to be the most abundant phytosterol (1048.9 $\pm 48.4 \mathrm{mg} / 100 \mathrm{~g}$ oil), followed by campesterol $(23.9 \pm 1.4 \mathrm{mg} / 100 \mathrm{~g}$ oil $)$, and neither stigmasterol or stigmastanol were present (Table 5). When determining the tocopherol composition of the oil, $\gamma$-tocopherol was found to be the most abundant compound of the class $(82.6 \pm 3.7 \mathrm{mg} / 100 \mathrm{~g}$ oil), followed by $\alpha$-tocopherol (19.6 $\pm 1.5 \mathrm{mg} / 100 \mathrm{~g}$ oil) (Table 5).

\section{Discussion}

\subsection{Extraction yield, fatty acid composition, and physicochemical properties}

The extraction yields obtained by either supercritical $\mathrm{CO}_{2}$ or Soxhlet extraction were within those found in previous research with different extraction techniques (Arain et al., 2017; Cerón et al., 2016; Da Silva and Jorge, 2014; Habib, 1986; Iha et al., 2018; Opute, 1978; Prasad and Azeemoddin, 1994) but lower than those reported for supercritical $\mathrm{CO}_{2}$ extraction with ethanol as a co-solvent (Castro-Vargas et al., 2011) (Table 1). Consistent with the abundance of linoleic acid found in this study, other oils obtained with supercritical $\mathrm{CO}_{2}$ or organic solvents contained linoleic acid $(52-79.4 \%, w / w)$ as the most abundant fatty acid, followed by comparable quantities of oleic acid $(7.8-14.0 \%, w /$ $w$ ), palmitic acid $(6.6-14.8 \%, w / w)$, and stearic acid $(3.4-16 \%, w / w)$, with low contributions of linolenic acid (Arain et al., 2017; Cerón et al., 2016; Da Silva and Jorge, 2014; Habib, 1986; Iha et al., 2018; Opute, 1978; Prasad and Azeemoddin, 1994). In contrast to our results, linoleic acid was present in a similar proportion to stearic acid when the oil was 

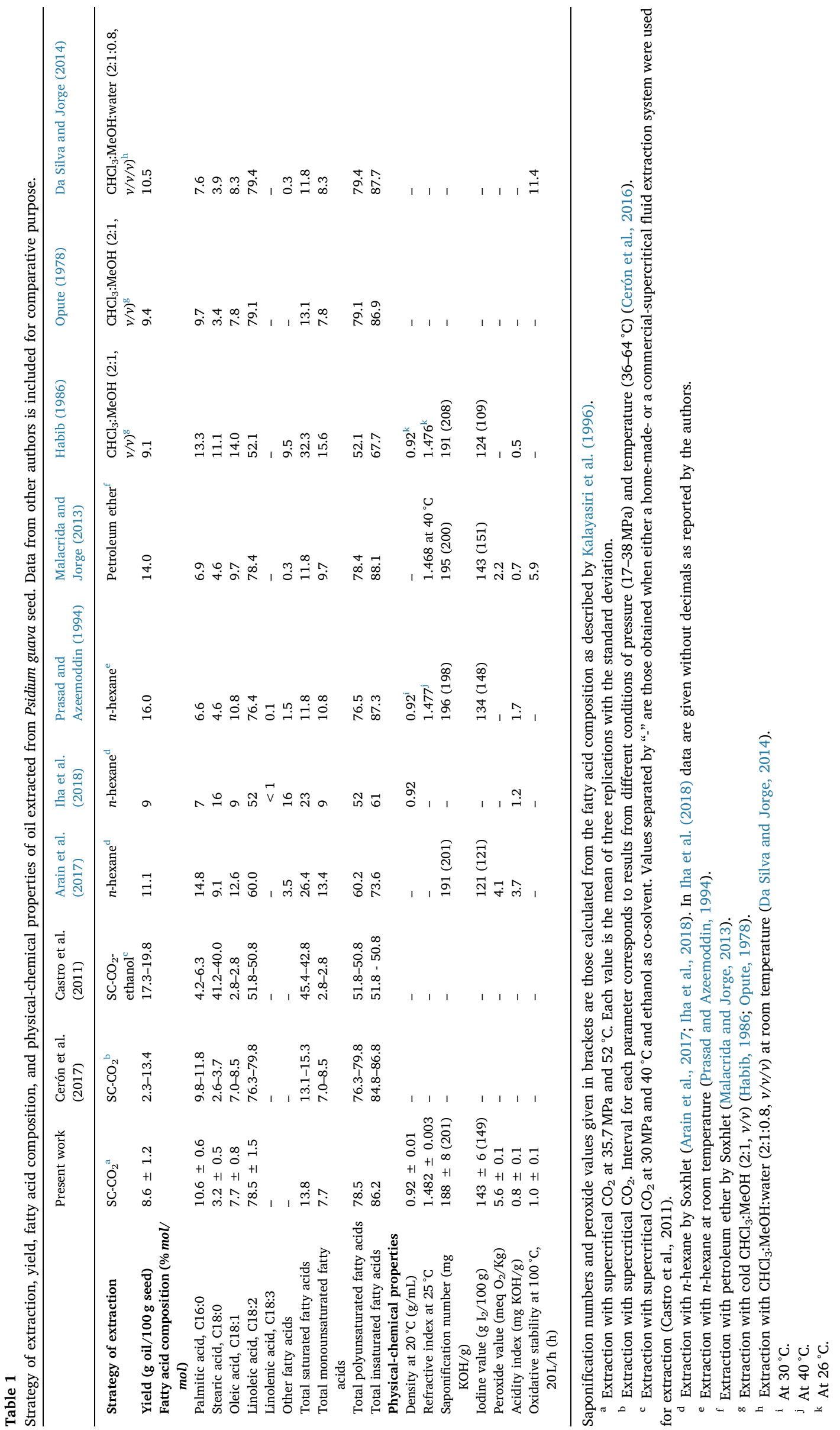


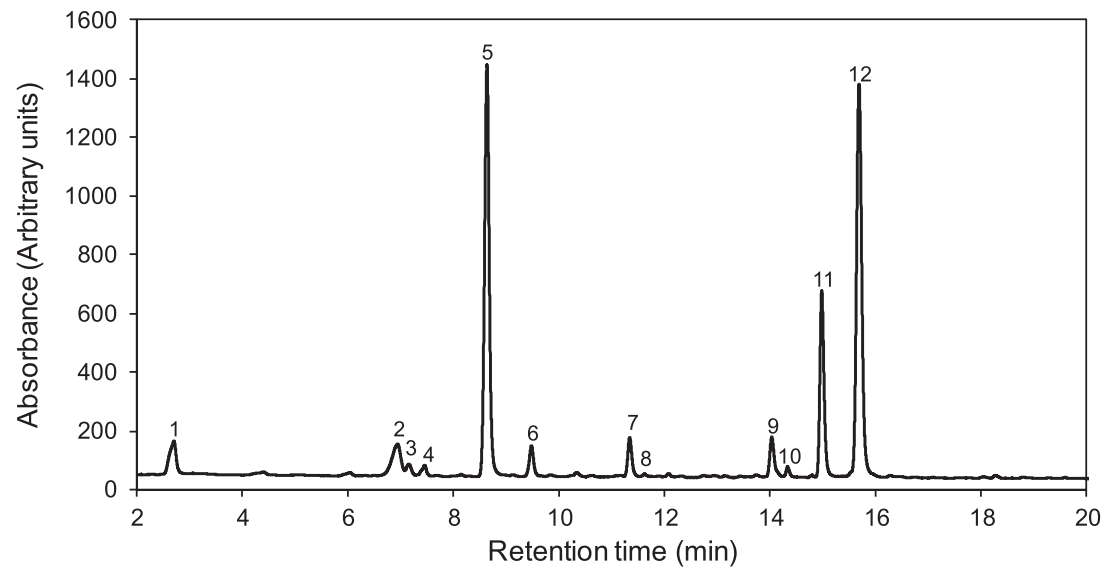

Fig. 1. RP-UHPLC chromatogram recorded at $284 \mathrm{~nm}$ of the guava seed oil, obtained by supercritical $\mathrm{CO}_{2}$ extraction, after liquid-liquid partitioning with methanol. For given numbers of each chromatographic peak refer to either Table 2 or Table 3.

obtained by supercritical $\mathrm{CO}_{2}$ extraction with ethanol as the co-solvent (Castro-Vargas et al., 2011). Despite the use of different extraction strategies, the density of guava seed oil obtained in the current research is similar to that reported in previous research, with refractive index and iodine values being higher than those reported previously (1.468-1.477, and 124-143 $\mathrm{g} \mathrm{I}_{2} / 100 \mathrm{~g}$ oil, respectively) (Table 1) (Arain et al., 2017; Iha et al., 2018; Habib, 1986; Malacrida and Jorge, 2013; Prasad and Azeemoddin, 1994). In agreement with our results, the saponification number and iodine value (Table 1) are similar to those previously reported $(191.0-196 \mathrm{mg} \mathrm{KOH} / \mathrm{g}$ oil and $121-143 \mathrm{~g}$ $\mathrm{I}_{2} / 100 \mathrm{~g}$, respectively) (Arain et al., 2017; Habib, 1986; Malacrida and Jorge, 2013; Prasad and Azeemoddin, 1994). The saponification number and iodine value of the obtained guava seed oil matched well with those calculated according to the fatty acid composition as described by Kalayasiri et al. (1996). The stability of lipids to the oxidation of guava seed oil as measured by the induction time by the Rancimat method was 5.9-fold lower than that reported when extracted by the Soxhlet method with petroleum ether (Malacrida and Jorge, 2013) and 11.4-fold lower than the value obtained when extracted with methanol:chloroform:water (2:1:0.8, $v / v / v)$ (Da Silva and Jorge, 2014). Furthermore, the obtained oil complied with the peroxide value and acidity index (Table 1) recommended for virgin oils by Codex Alimentarius (1999), as these two parameters were lower than 15 meq $\mathrm{O}_{2} / \mathrm{kg}$ oil and $4.0 \mathrm{mg} \mathrm{KOH} / \mathrm{g}$, respectively.

Differences observed in extraction yield, fatty acid composition, and physicochemical properties found between the current research and previous reports might be related not only to the marked differences in extraction strategies (as shown in Table 1) but also to the variety and agro-climatic conditions of cultivation. In this regard, oils obtained from 25 different varieties of pomegranate (Punica granatum L.) seeds had a 2.9-fold difference in yield and a large variability in fatty acid profiles. In this profile, linolenic acid was the most abundant fatty acid, followed by linoleic acid, exhibiting a 2.7 -fold change and a 35 -fold change, respectively (Fadavi et al., 2006). Agro-climatic conditions of cultivation might also have an impact on both the yield and relative abundance of fatty acids, as shown in oil extracted from chia seeds (Salvia hispanica L.); when cultivated in five agro-climatic conditions, there was a 1.2-fold change in yield and linoleic acid abundance, the most abundant fatty acid (Ayerza, 1995).

A differential effect on the type and concentration of individual phenolic compounds and the concentration of phytosterols and tocopherols in guava seed oil was observed when extracted by supercritical $\mathrm{CO}_{2}$ extraction, which was used in the current research, compared to that involving organic solvents (Da Silva and Jorge, 2014; Malacrida and Jorge, 2013; Piombo, 2006). Despite higher concentrations of individual phenolic compounds, $\alpha$-tocopherol, and $\gamma$-tocopherol were obtained in the oil extracted by supercritical $\mathrm{CO}_{2}$ extraction than by organic solvents, a lower oxidation stability was observed (as evaluated by the Rancimat test). The lower stability of guava seed oil extracted with supercritical $\mathrm{CO}_{2}$ might be related not only to the presence of prooxidants, such as chlorophylls and reducing compounds but also to the raw nature of such oil, where phenolic compounds can act as pro-oxidants depending on their concentration (Ospina et al., 2019).

Table 2

Identification of compounds present in a methanolic extract of guava seed oil obtained by supercritical $\mathrm{CO}_{2}$ as determined by UHPLC-DAD-HESI-MS/MS.

\begin{tabular}{|c|c|c|c|c|c|c|}
\hline Peak number & $\mathrm{R}_{\mathrm{T}}(\min )$ & $\begin{array}{l}\text { Parent ion }[\mathrm{M}-\mathrm{H}]^{-} /[\mathrm{M}+\mathrm{H}]^{+} \\
(m / z)\end{array}$ & $\mathrm{MS}^{2}$ negative ion mode $(\mathrm{m} / \mathrm{z})^{\mathrm{a}}$ & $\mathrm{MS}^{2}$ positive ion mode $(m / z)^{\mathrm{a}}$ & $\begin{array}{l}\text { UV } \lambda \text { max } \\
(\mathrm{nm})\end{array}$ & Tentative annotation \\
\hline 1 & 2.71 & - & - & - & 284 & Not identified \\
\hline 2 & 6.95 & $167 / 169$ & $123,108(26)$ & 125, $110(2), 93(22)$ & 292 & Vanillic acid ${ }^{\mathrm{b}}$ \\
\hline 3 & 7.16 & $121 / 123$ & 121,94 (4), $92(2)$ & $95(31), 82$ & 284 & 4-Hydroxybenzaldehyde ${ }^{\mathrm{b}}$ \\
\hline 4 & 7.46 & - & - & - & 276,303 & Not identified \\
\hline 5 & 8.64 & $151 / 153$ & $151,136(2), 123(15), 107(22)$ & $125,93(11)$ & 280,308 & Vanillin ${ }^{\mathrm{b}}$ \\
\hline 6 & 9.48 & $181 / 183$ & $181(15), 151,137$ (19) & $155,142(4), 123(22)$ & 308 & Syringaldehyde $^{\mathrm{b}}$ \\
\hline 7 & 11.34 & $177 / 179$ & $\begin{array}{l}\text { 177, } 162(22), 149(4), 134(7), 106 \\
\text { (4) }\end{array}$ & 151(4), 147,133 (26), 105 (7) & 340 & Coniferylaldehyde $^{\mathrm{b}}$ \\
\hline 8 & 11.62 & $207 / 209$ & $207(26), 192(2), 177,163(4)$ & $\begin{array}{l}181 \text { (11), 177, } 149 \text { (19), } 131 \\
(11)\end{array}$ & 345 & Sinapaldehyde ${ }^{b}$ \\
\hline 9 & 14.03 & - & - & - & 282 & Not identified \\
\hline 10 & 14.33 & $263 /-$ & 219 (54), 204 (10), 153 & - & 270 & Abscisic acid \\
\hline 11 & 14.98 & $147 / 149$ & $103,147(4)$ & 149 (6), 131(12), 121(16), 103 & 276 & Cinnamic acid $^{\mathrm{b}}$ \\
\hline 12 & 15.68 & $-/ 133$ & - & 134 (16), 105 (26), 91 (12), 55 & 289 & Cinnamaldehyde $^{\mathrm{b}}$ \\
\hline
\end{tabular}

${ }^{\text {a }} \mathrm{MS}^{2}$ base peak is shown in bold. Relative abundance is given in brackets.

b Retention time, parent ion, daughter ions (in negative and positive mode), and UV spectra matching those of authentic standards. 
Table 3

Accurate mass data and empirical formula of compounds present in a methanolic extract of guava seed oil obtained by supercritical $\mathrm{CO}_{2}$ as determined by UHPLCESI-IT-FTMS.

\begin{tabular}{|c|c|c|c|c|c|c|}
\hline Peak number & Compound & Ionization & $m / z$ observed & Molecular formula & $m / z$ expected & Error (ppm) \\
\hline 1 & Not identified & & & & & \\
\hline 2 & Vanillic acid & {$[\mathrm{M}-\mathrm{H}]^{+}$} & 169.0495 & $\mathrm{C}_{8} \mathrm{H}_{8} \mathrm{O}_{4}$ & 169.0501 & -3.7 \\
\hline 3 & 4-Hydroxybenzaldehyde & {$[\mathrm{M}-\mathrm{H}]^{-}$} & 121.0296 & $\mathrm{C}_{7} \mathrm{H}_{6} \mathrm{O}_{2}$ & 121.0290 & 5.2 \\
\hline 4 & Not identified & & & & & \\
\hline 5 & Vanillin & {$[\mathrm{M}-\mathrm{H}]^{-}$} & 151.0400 & $\mathrm{C}_{8} \mathrm{H}_{8} \mathrm{O}_{3}$ & 151.0395 & 3.5 \\
\hline 6 & Syringaldehyde & {$[\mathrm{M}-\mathrm{H}]^{-}$} & 181.0507 & $\mathrm{C}_{9} \mathrm{H}_{10} \mathrm{O}_{4}$ & 181.0501 & 3.3 \\
\hline 7 & Coniferylaldehyde & {$[\mathrm{M}-\mathrm{H}]^{-}$} & 177.0557 & $\mathrm{C}_{10} \mathrm{H}_{10} \mathrm{O}_{3}$ & 177.0552 & 3.2 \\
\hline 8 & Sinapaldehyde & {$[\mathrm{M}+\mathrm{H}]^{+}$} & 209.0807 & $\mathrm{C}_{11} \mathrm{H}_{12} \mathrm{O}_{4}$ & 209.0814 & -3.2 \\
\hline 9 & Not identified & & & & & \\
\hline 10 & Abscisic acid & {$[\mathrm{M}-\mathrm{H}]^{-}$} & 263.1289 & $\mathrm{C}_{15} \mathrm{H}_{20} \mathrm{O}_{4}$ & 263.1283 & 2.3 \\
\hline 11 & Cinnamic acid & {$[\mathrm{M}+\mathrm{H}]^{+}$} & 149.0597 & $\mathrm{C}_{9} \mathrm{H}_{8} \mathrm{O}_{2}$ & 149.0602 & -3.6 \\
\hline 12 & Cinnamaldehyde & {$[\mathrm{M}+\mathrm{H}]^{+}$} & 133.0648 & $\mathrm{C}_{9} \mathrm{H}_{8} \mathrm{O}$ & 133.0653 & -4.3 \\
\hline
\end{tabular}

Table 4

Quantification of individual compounds present in a methanolic extract of guava seed oil obtained by supercritical $\mathrm{CO}_{2}$.

\begin{tabular}{ll}
\hline Compound & Content $(\mathrm{mg} / 100 \mathrm{~g}$ oil) \\
\hline Phenolic compounds & $3.9 \pm 0.4$ \\
Vanillic acid & $0.2 \pm 0.0$ \\
4-Hydroxybenzaldehyde & $9.6 \pm 0.3$ \\
Vanillin & $1.2 \pm 0.1$ \\
Syringaldehyde & $1.5 \pm 0.0$ \\
Coniferylaldehyde & $0.3 \pm 0.0$ \\
Sinapaldehyde & $16.7 \pm 0.3$ \\
Total amount of phenolics & \\
Miscellaneous compounds & $2.4 \pm 0.1$ \\
Cinnamic acid & $9.4 \pm 0.2$ \\
Cinnamaldehyde & \\
\hline
\end{tabular}

Each value is the mean of three replications with the standard deviation.

Table 5

Phytosterols and tocopherols present in oil extracted from Psidium guava seed (mg/100 g oil).

\begin{tabular}{lllll}
\hline Compound & Present work $^{\mathrm{a}}$ & $\begin{array}{l}\text { Da Silva and } \\
\text { Jorge } \\
(2014)^{\mathrm{b}}\end{array}$ & $\begin{array}{l}\text { Piombo } \\
\text { et al. } \\
(2006)^{\mathrm{c}}\end{array}$ & $\begin{array}{l}\text { Malacrida and } \\
\text { Jorge }(2013)^{\mathrm{d}}\end{array}$ \\
\hline $\begin{array}{l}\text { Phytosterols } \\
\text { Campesterol }\end{array}$ & $23.9 \pm 1.4$ & - & & \\
$\beta$-sitosterol & $1048.9 \pm 48.4$ & 437.6 & 9.9 & - \\
Stigmasterol & - & - & traces & - \\
Stigmastanol & - & 26.6 & 319.1 & - \\
Tocopherols & & & - & - \\
$\alpha$-tocopherol & $19.6 \pm 1.5$ & 4.6 & 10.7 & 7.1 \\
ß-tocopherol & - & $*$ & 0.3 & - \\
$\gamma$-tocopherol & $82.6 \pm 3.7$ & 9.3 & 55.0 & 20.3 \\
$\delta$-tocopherol & - & $*$ & 0.5 & - \\
\hline
\end{tabular}

a Extraction with supercritical $\mathrm{CO}_{2}$ at $35.7 \mathrm{MPa}$ and $52^{\circ} \mathrm{C}$. Each value is the mean of three replications with the standard deviation.

b Extraction with $\mathrm{CHCl}_{3}: \mathrm{MeOH}$ :water $(2: 1: 0.8, v / v / v)$ at room temperature (Da Silva and Jorge, 2014).

c Acelerated solvent extraction with petroleum ether at $10.0 \mathrm{MPa}$ and $80{ }^{\circ} \mathrm{C}$ (Piombo et al., 2006).

${ }^{d}$ Extraction with petroleum ether by Soxhlet (Malacrida and Jorge, 2013).

* Authors report $0.3 \mathrm{mg}$ ß-tocopherol $+\delta$-tocopherol mg/100 g oil.

\subsection{Diversity of phenolic compounds}

The phenolic profile obtained in guava seed oil was found to be composed of phenolic aldehydes and a phenolic acid. Furthermore, chromatographic peaks 1, 4, and 9 had UVmax values that might correspond to phenolic compounds (Sakakibara et al., 2003); nevertheless, no further annotation could be done, as MS information could not be obtained. Composition of phenolic compounds found in the current work contrasts with the profile reported for other parts of the plant. These differences are evident in terms of the type and number of representatives. A total of 72 phenolic compounds were found in extracts prepared from guava leaves, including benzoic acids, flavonols, flavan3-ols, flavanones, and proanthocyanidins (Díaz-de-Cerio et al., 2016). In the sub-class of benzoic acids reported in guava leaves, the only compound of this class that was found in the current research was gallic acid. Although less diverse in the number of compounds, in guava pulp, a total of 14 phenolic compounds were found, including anthocyanins, flavonoids, and proanthocyanidins (Flores et al., 2015). In the oil extracted from guava seeds, a simple phenolic profile composed of three compounds was reported (Da Silva and Jorge, 2014). That phenolic profile included salicylic acid, $p$-coumaric acid, and quercetin, which are representatives of the sub-classes of benzoic acids, hydroxycinnamic acids, and flavonoids, respectively.

The totally different phenolic profile found in this study compared to those described in guava leaves (Díaz-de-Cerio et al., 2016), guava pulp (Flores et al., 2015), and oil extracted from guava seeds (Da Silva and Jorge, 2014) might reflect differences in the extraction method, more so than differences in the analysed botanical parts, agro-climatic conditions of cultivation or variety. While guava leaves were extracted in an ultrasonic bath with ethanol:water (80:20, $v / v$ ) (Díaz-de-Cerio et al., 2016), extraction of guava pulp was performed with methanol:water:formic acid (70:25:5, v:v:v) at room temperature (Flores et al., 2015), and guava seeds were extracted by cold extraction with chloroform:methanol:water (2:1:0.8, $v / v / v)$ (Da Silva and Jorge, 2014). The enormous influence of the nature of the solvents used for extraction on the phenolic composition (concentration and representatives) of different botanical parts of guava contrast with the similarity in the phenolic composition of different botanical parts of cherry plum (Prunus $\times$ domestica L.) (Khallouki et al., 2012).

The solubility of phenolic compounds depends on different thermodynamic parameters, with supercritical conditions playing an important role. Far below supercritical conditions, that is, near atmospheric pressure conditions, the enthalpy of fusion, melting temperature, and difference between the liquid and solid molar heat capacities of the solute are important thermodynamic features commanding the solubility of phenolic compounds (Queimada et al., 2009). In contrast, when above supercritical conditions, there are totally different parameters that are involved in the solubility of a compound. These parameters include critical temperature, critical pressure, molar volume, and acentric factor (Dadkhah et al., 2017). Therefore, differences in parameters governing the solubility of phenolic compounds might explain the differences observed in the chromatographic profile when oil was extracted by either organic solvents (Da Silva and Jorge, 2014) or by supercritical $\mathrm{CO}_{2}$, as in the current research. In this regard, peach almond oil contained benzaldehyde ( $15 \%$ of the total chromatographic area) when extraction was performed by the Soxhlet method with $n$-hexane:dichlorometane $(1: 1, v: v)$, while this compound was not 
detected when extracted with supercritical $\mathrm{CO}_{2}$ (either at $200 \mathrm{bar} /$ $40{ }^{\circ} \mathrm{C}, 300 \mathrm{bar} / 40^{\circ} \mathrm{C}$, or $\left.300 \mathrm{bar} / 50^{\circ} \mathrm{C}\right)$. Furthermore, a similar comparison shows that while 2,4-bis(1,1-dimethylethyl)-phenol was not detected when extraction was performed by the Soxhlet method or by supercritical $\mathrm{CO}_{2}$ (either at $20.0 \mathrm{MPa} / 40{ }^{\circ} \mathrm{C}$ or $30.0 \mathrm{MPa} / 40{ }^{\circ} \mathrm{C}$ ), it was found $(0.4 \%$ of the total chromatographic area) when extraction by supercritical $\mathrm{CO}_{2}$ was conducted at $30.0 \mathrm{MPa} / 40^{\circ} \mathrm{C}$ (Mezzomo et al., 2010). Vanillin and vanillic acid, relatively polar compounds found in guava seed oil extracted by supercritical $\mathrm{CO}_{2}$, are soluble in supercritical $\mathrm{CO}_{2}$, with increasing solubility as pressure and temperature are increased (Rojas-Ávila et al., 2016).

Interestingly, vanillin and cinnamaldehyde, found in comparable quantities in the extracted guava seed oil, have promising bio-activities. While vanillin improves insulin resistance in metabolic diseases, such as obesity, type 2 diabetes, and hyperlipidaemia (Park et al., 2011), cinnamaldehyde has hypoglycaemic and hypolipidaemic activities (Babu et al., 2007) as well as activity against the human gastric pathogen Helicobacter pylori (Ali et al., 2005).

The total amount of individual phenolic compounds $(16.7 \pm 0.3 \mathrm{mg} / 100 \mathrm{~g}$ oil) (Table 4$)$ was higher than the value obtained after adding the individual contents of $p$-coumaric acid, salicylic acid, and quercetin $(9.9 \mathrm{mg} / 100 \mathrm{~g}$ oil) together when extracted with organic solvents by cold extraction (Da Silva and Jorge, 2014). The total phenolic content in guava seed oil $(263.1 \pm 18.7 \mathrm{mg}$ gallic acid equivalents $/ 100 \mathrm{~g}$ oil) extracted by supercritical $\mathrm{CO}_{2}$ was much higher than the values reported previously when the oil was obtained by cold extraction with chloroform:methanol:water (2:1:0.8 $\quad v / v / v)$ (27.2 $\pm 0.2 \mathrm{mg}$ gallic acid equivalents/100 $\mathrm{g}$ oil) (Da Silva and Jorge, $2014)$ or with petroleum ether by Soxhlet $(29.3 \pm 0.3 \mathrm{mg}$ gallic acid equivalents/100 g oil) (Malacrida and Jorge, 2013). The overestimation of phenolic compounds by the Folin-Ciocalteu method compared to the RP-UHPLC-DAD method has been reported previously in crude extracts and is related to the involved redox reaction itself. In such reactions, not only phenolic compounds but also other compounds with redox potentials high enough to reduce the Folin-Ciocalteu reagent, including reducing sugars, vitamin $\mathrm{C}$, chlorophylls, amino acids, proteins, and carboxylic acids, are measured (Castro-Alves and Cordenunsi, 2015; Everette et al., 2010).

\subsection{Diversity of phytosterols and tocopherols}

In agreement with our results, $\beta$-sitosterol was the main phytosterol found in guava seed oil when extracted with chloroform:methanol:water $(2: 1: 0.8, v / v / v)$ at room temperature, but the concentration of this compound was 2.4-times higher in the current research than in the previous report (Da Silva and Jorge, 2014). In contrast to the results of this study, stigmasterol was the main phytosterol in oil extracted from guava seeds when extracted with petroleum ether by accelerated solvent extraction (Piombo et al., 2006). Furthermore, the high relative abundance of $\gamma$-tocopherol and $\alpha$-tocopherol agrees with that reported in previous reports when guava seed oil was obtained with chloroform:methanol:water (2:1:0.8, $v / v / v)$ (Da Silva and Jorge, 2014), petroleum ether by accelerated solvent extraction (Piombo et al., 2006) or petroleum ether by Soxhlet (Malacrida and Jorge, 2013).

The higher abundances of $\gamma$-tocopherol and $\beta$-sitosterol found in guava seed oil extracted by supercritical $\mathrm{CO}_{2}$ than in guava seed oil obtained with organic solvents might be of interest from a health point of view. Beyond the vitamin E activity of tocopherols, $\gamma$-tocopherol has anti-inflammatory properties (Jiang and Ames, 2003), which might reduce the incidence of coronary heart disease (Lemcke-Norojärvi et al., 2001). Phytosterols, especially $\beta$-sitosterol, are known to have cholesterol-lowering effects as well as anti-inflammatory effects, which may offer protection against coronary artery disease (Othman and Moghadasian, 2011).

\section{Conclusion}

An edible oil obtained by supercritical $\mathrm{CO}_{2}$ extraction was characterized and exhibited a unique phenolic and miscellaneous compound profile, a high proportion of $\beta$-sitosterol compared to that of the other phytosterols, a high contribution of $\gamma$-tocopherol to the tocopherol composition, a high contribution of linoleic acid to the fatty acid profile, and low stability to lipid oxidation. Within the phenolic and miscellaneous compound profile, vanillin and cinnamaldehyde were the most abundant, followed by vanillic acid and cinnamic acid. Overall, given the composition of bioactive compounds and the low oxidative stability, guava seed oil extracted by supercritical $\mathrm{CO}_{2}$ might have applications in the food industry, directly or after blending with more stable edible oils, as a dressing for salads but not for cooking, e.g., frying.

\section{CRediT authorship contribution statement}

Carlos-Eduardo Narváez-Cuenca: Investigation, Writing - original draft, Writing - review \& editing. Mary-Lucía Inampues-Charfuelan: Conceptualization, Investigation, Validation. Andrés-Mauricio Hurtado-Benavides: Conceptualization, Resources, Supervision, Funding acquisition. Fabián Parada-Alfonso: Conceptualization, Resources, Writing - review \& editing. Jean-Paul Vincken: Conceptualization, Resources, Writing - review \& editing.

\section{Declaration of Competing Interest}

None.

\section{Acknowledgements}

The authors are grateful to the Fundación Centro de Estudios Interdisciplinarios, Básicos y Aplicados (CEIBA), Nariño Government, and Sistema General de Regalías de Colombia for providing a fellowship to M.-L. Inampues-Charfuelan for supporting this work and to Andina de conservas LTDA for providing the guava seeds. The authors thank the Faculty of Sciences, Universidad Nacional de Colombia, for providing financial support to C.-E. Narváez-Cuenca for his academic stay at Wageningen University to perform experiments on the identification and quantification of individual phenolic compounds. The technical assistance provided by David Arturo (Universidad de Nariño) and critical reading of the manuscript by Andrea del Pilar Sánchez (Universidad Nacional de Colombia) are gratefully acknowledged.

\section{Appendix A. Supplementary data}

Supplementary material related to this article can be found, in the online version, at doi:https://doi.org/10.1016/j.jfca.2020.103467.

\section{References}

Agronet. (2019). https://www.agronet.gov.co/estadistica/Paginas/home.aspx? $\operatorname{cod}=1$. (Accessed on February 2019).

Ali, S.M., Khan, A.A., Ahmed, I., Musaddiq, M., Ahmed, K.S., Polasa, H., Rao, L.V., Habibullah, C.M., Sechi, L.A., Ahmed, N., 2005. Antimicrobial activities of eugenol and cinnamaldehyde against the human gastric pathogen Helicobacter pylori. Ann. Clin. Microbiol. Antimicrob. 4 (1), 20.

Alimentarius, C., 1999. Codex standard for named vegetable oils. Codex Stan 210, 1-13. AOCS, Firestone, D., 2009. Official Methods and Recommended Practices of the American Oil Chemist's Society. AOCS Press, Champaign, USA.

Arain, A., Sherazi, S.T.H., Mahesar, S.A., Sirajuddin, 2017. Spectroscopic and chromatographic evaluation of solvent extracted guava seed oil. Int. J. Food Prop. 20 (sup1), S556-S563.

Association of Official Analytical (AOAC), 1995. Official Methods of Analysis, 16th ed. AOAC International, Gaithersburg, MD.

Ayerza, R., 1995. Oil content and fatty acid composition of chia (Salvia hispanica L.) from five northwestern locations in Argentina. J. Am. Oil Chem. Soc. 72, 1079-1081.

Babu, P.S., Prabuseenivasan, S., Ignacimuthu, S., 2007. Cinnamaldehyde-A potential antidiabetic agent. Phytomedicine 14 (1), 15-22. 
Barbalho, S.M., Farinazzi-Machado, F.M.V., de Alvares Goulart, R., Brunnati, A.C., Otoboni, A.M., Ottoboni, B., 2012. Psidium guajava (Guava): a plant of multipurpose medicinal applications. Medicinal and Aromatical Plants 1 (104) 2167-0412.

Castro-Alves, V.C., Cordenunsi, B.R., 2015. Total soluble phenolic compounds quantification is not as simple as it seems. Food Anal. Methods 8 (4), 873-884.

Castro-Vargas, H.I., Rodríguez-Varela, L.I., Parada-Alfonso, F., 2011. Guava (Psidium guajava L.) seed oil obtained with a homemade supercritical fluid extraction system using supercritical $\mathrm{CO}_{2}$ and co-solvent. J. Supercrit. Fluids 56 (3), 238-242.

Cerón, L.J., Hurtado, A.M., Ayala, A.A., 2016. Efecto de la presión y la temperatura de extracción con $\mathrm{CO}_{2}$ supercrítico sobre el rendimiento y composición de aceite de semilla de guayaba (Psidium guajava). Inf. Tecnolã $\tilde{3}^{3}$ gica 27 (6), 249-258.

Da Silva, A.C., Jorge, N., 2014. Bioactive compounds of the lipid fractions of agro-industrial waste. Food Res. Int. 66, 493-500.

Dadkhah, M.R., Tatar, A., Mohebbi, A., Barati-Harooni, A., Najafi-Marghmaleki, A., Ghiasi, M.M., Mohammadi, A.H., Pourfayaz, F., 2017. Prediction of solubility of solid compounds in supercritical $\mathrm{CO}_{2}$ using a connectionist smart technique. J. Supercrit. Fluids 120, 181-190.

Díaz-de-Cerio, E., Gómez-Caravaca, A.M., Verardo, V., Fernández-Gutiérrez, A., SeguraCarretero, A., 2016. Determination of guava (Psidium guajava L.) leaf phenolic compounds using HPLC-DAD-OTOF-MS. J. Funct. Foods 22, 376-388.

Everette, J.D., Bryant, Q.M., Green, A.M., Abbey, Y.A., Wangila, G.W., Walker, R.B., 2010. Thorough study of reactivity of various compound classes toward the FolinCiocalteu reagent. J. Agric. Food Chem. 58 (14), 8139-8144.

Fadavi, A., Barzegar, M., Azizi, M.H., 2006. Determination of fatty acids and total lipid content in oilseed of 25 pomegranates varieties grown in Iran. J. Food Compos. Anal. 19 (6-7), 676-680.

Flores, G., Wu, S.B., Negrin, A., Kennelly, E.J., 2015. Chemical composition and antioxidant activity of seven cultivars of guava (Psidium guajava) fruits. Food Chem. 170, 327-335.

Habib, M.A., 1986. Studies on the lipid and protein composition of guava seeds (Psidium guajava). Food Chem. 22 (1), 7-16.

Hurtado-Benavides, A., Dorado, D.A., Sánchez-Camargo, A.D.P., 2016. Study of the fatty acid profile and the aroma composition of oil obtained from roasted Colombian coffee beans by supercritical fluid extraction. J. Supercrit. Fluids 113, 44-52.

Iha, O.K., Martins, G.B., Ehlert, E., Montenegro, M.A., Sucupira, R.R., Suarez, P.A., 2018. Extraction and characterization of passion fruit and guava oils from industrial residual seeds and their application as biofuels. J. Braz. Chem. Soc. 29 (10), 2089-2095.

Jiang, Q., Ames, B.N., 2003. $\gamma$-Tocopherol, but not $\alpha$-tocopherol, decreases proinflammatory eicosanoids and inflammation damage in rats. Faseb J. 17 (8), 816-822.

Kalayasiri, P., Jeyashoke, N., Krisnangkura, K., 1996. Survey of seed oils for use as diesel fuels. J. Am. Oil Chem. Soc. 73 (4), 471-474.

Khallouki, F., Haubner, R., Erben, G., Ulrich, C.M., Owen, R.W., 2012. Phytochemical composition and antioxidant capacity of various botanical parts of the fruits of Prunus $\times$ domestica L. From the Lorraine region of Europe. Food Chem. 133 (3), 697-706.
Lemcke-Norojärvi, M., Kamal-Eldin, A., Appelqvist, L.A., Dimberg, L.H., Öhrvall, M., Vessby, B., 2001. Corn and sesame oils increase serum $\gamma$-tocopherol concentrations in healthy Swedish women. J. Nutr. 131 (4), 1195-1201.

Malacrida, C., Jorge, N., 2013. Fatty acids and some antioxidant compounds of Psidium guajava seed oil. Acta Aliment. 42 (3), 371-378.

Matthaus, B., Ozcan, M., 2011. Determination of fatty acid, tocopherol, sterol contents and 1,2- and 1,3-diacyglycerols in four different virgen olive oil. Food Process Technology 2 (4), 1-4.

Medina, N.N.R., Herrero, J.V.I., 2016. Guava (psidium guajava L.) Cultivars: an important source of nutrients for human health. In Nutritional Composition of Fruit Cultivars. pp. 287-315.

Mezzomo, N., Mileo, B.R., Friedrich, M.T., Martínez, J., Ferreira, S.R., 2010. Supercritical fluid extraction of peach (Prunus persica) almond oil: process yield and extract composition. Bioresour. Technol. 101 (14), 5622-5632.

Opute, F.I., 1978. The component fatty acids of Psidium guajava seed fats. J. Sci. Food Agric. 29 (8), 737-738.

Ospina, M., Montaña-Oviedo, K., Díaz-Duque, Á., Toloza-Daza, H., Narváez-Cuenca, C.E., 2019. Utilization of fruit pomace, overripe fruit, and bush pruning residues from Andes berry (Rubus glaucus Benth) as antioxidants in an oil in water emulsion. Food Chem. 281, 114-123.

Othman, R.A., Moghadasian, M.H., 2011. Beyond cholesterol-lowering effects of plant sterols: clinical and experimental evidence of anti-inflammatory properties. Nutr. Rev. 69 (7), 371-382.

Park, S., Kim, D.S., Kang, S., 2011. Gastrodia elata Blume water extracts improve insulin resistance by decreasing body fat in diet-induced obese rats: vanillin and 4-hydroxybenzaldehyde are the bioactive candidates. Eur. J. Nutr. 50 (2), 107-118.

Piombo, G., Barouh, N., Barea, B., Boulanger, R., Brat, P., Pina, M., Villeneuve, P., 2006. Characterization of the seed oils from kiwi (Actinidia chinensis), passion fruit (Passiflora edulis) and guava (Psidium guajava). Oilseeds and Fats, Crops and Lipids 13 (2-3), 195-199.

Prasad, N.B.L., Azeemoddin, G., 1994. Characteristics and composition of guava (Psidium guajava L.) seed and oil. J. Am. Oil Chem. Soc. 71 (4), 457-458.

Queimada, A.J., Mota, F.L., Pinho, S.P., Macedo, E.A., 2009. Solubilities of biologically active phenolic compounds: measurements and modeling. J. Phys. Chem. B 113 (11), 3469-3476.

Rojas-Ávila, A., Pimentel-Rodas, A., Rosales-García, T., Dávila-Ortiz, G., Galicia-Luna, L.A., 2016. Solubility of binary and ternary systems containing vanillin and vanillic acid in supercritical carbon dioxide. J. Chem. Eng. Data 61 (9), 3225-3232.

Sahena, F., Zaidul, I.S.M., Jinap, S., Karim, A.A., Abbas, K.A., Norulaini, N.A.N., Omar, A.K.M., 2009. Application of supercritical CO2 in lipid extraction-A review. J. Food Eng. 95 (2), 240-253.

Sakakibara, H., Honda, Y., Nakagawa, S., Ashida, H., Kanazawa, K., 2003. Simultaneous determination of all polyphenols in vegetables, fruits, and teas. J. Agric. Food Chem. 51 (3), 571-581.

Waterhouse, A.L., 2002. Determination of total phenolics. Current Protocols in Food Analytical Chemistry 6 (1), I1-1. 